\title{
Control of Ideally Expanded and under Expanded Nozzle Flows with Micro Jets
}

\author{
Fharukh Ahmed G M${ }^{1}$, M. Ahmed Ali Baig ${ }^{2}$, Musavir Bashir ${ }^{3}$, S. A. Khan ${ }^{4}$ \\ ${ }^{1}$ Assistant Professor, Department of Mechanical Engineering, Government Engineering College, Huvinahadagali, \\ Karnataka \\ ${ }^{2}$ Professor, Department of Mechanical Engineering, CMR Technical Campus, Hyderabad \\ ${ }^{3}$ Research Scholar, School of Aerospace Engineering, USM, Penang, Malaysia \\ ${ }^{4}$ Professor, Department of Mechanical Engineering, Faculty of Engineering, IIUM, Kuala Lumpur, Malaysia
}

\begin{abstract}
This paper presents an experimental investigation of an airflow from convergent-divergent axisymmetric nozzles expanded suddenly into circular duct of larger cross-sectional area than that of nozzle exit area, focusing attention on the base pressure and the flow development in the duct. To investigate the influence of active control on wall pressure as well as on the flow field developed in the duct, the micro jets of $1 \mathrm{~mm}$ orifice diameter located at $90^{\circ}$ interval along a pitch circle diameter 1.3 times the nozzle exit diameter were employed as the controller of the base pressure. The Mach number investigated in the present study was 1.30. The area ratio of the present study was 2.56. The nozzle pressure ratio (NPR) used were from 2.77 and 4.16 respectively which corresponds to correct and under expanded conditions. The length-to-diameter ratio of the enlarged duct was varied from 10 to 1.The level of expansion at the nozzle exit (i.e. before sudden expansion) influences the wall pressure very strongly. When the micro jets were activated they found to influence the flow in the enlarged duct. Wall pressure results for correctly expanded and under expended jets indicate that the flow in the enlarged duct remains attached for $L / D$ s including at $L / D=1$. Also, it is found that the wall pressure flow field in the duct for with and without control are identical and the control in the form of the micro jets does disturb the flow field. Results for $L / D=8$ and 10 for correctly expanded jets indicate peculiar phenomenon and are totally different from all the results for lower $L / D$ s. Wall pressure results for under expanded jets indicate that control results in marginal decrease in the wall pressure otherwise the wall pressure flow field with and without control remains same.
\end{abstract}

\section{Introduction}

THE flow field generated by the infringement of high-speed flows usually results in a very unsteady flow field. When such flows are generated at the rear end of aerospace vehicles, this flow can lead to a host of adverse effects that can diminish aircraft performance. One of the important related issues is the occurrence of base flow aerodynamic side loads due to vortex shedding and asymmetric flow separation inside a rocket nozzle. This problem has been well studied through experiments as well as computations. The unsteady separation phenomenon inside the nozzle can lead to steady/unsteady forcing of the thrusting nozzle, as well as associated mechanisms due to fluid-structure interactions [1-5]. The presence of such unsteady side loads can also result in adverse control systems of the vehicle in pitch, roll, and yaw [6]. Since the nozzle is located in the wake of the main body, response of the nozzle and the associated mechanical systems to the oscillating outer flow in the presence of asymmetric loading due to internal flow has been studied $[4,7,8]$. The investigations have demonstrated the origin of these unsteady phenomena at the base of the nozzle are 1) asymmetric separation line, 2) pressure pulsations at the separation and reattachment locations, 3) aeroelastic coupling, 4) transition of separation pattern between restricted shock separation (RSS) and full shock separation (FSS), and 5) external flow instabilities such as buffeting[9]. A computational approach to model the fluid-structure interactions of the one such nozzle using detached-eddy simulations coupled with second-order structural computations for different nozzle configurations has been studied [10].

In fluid dynamics research community, the efficient and effective control of turbulent flow has turned an upcoming goal. Innumerous applications of turbulence flow control include viscous drag reduction in numerous aerodynamic and hydrodynamic applications, regulation of heat transfer, reduction of wall pressure fluctuations and flow-generated noise, reduced oscillation and unsteadiness in resonance-dominated flows, and so on. These control techniques are also used to delay the transition to turbulence, and prevention/delay of boundary-layer separation in various internal and external flows leading to performance loss. The interaction of pressure distribution in the expansion corner with the boundary layer and thickness of upstream flow was studied by Wick[11]. Boundary layer is a cause of fluid for the corner flow and it was found that air expands 
abruptly after passing through a convergent nozzle. The under expanded gas jets from the blunt bodies was seen to produce a shock structure by applying numerical studies by Menon and Skews[12]. This shock structure was affected by the corners of the nozzle and barrel shocks were observed in the nozzle exit by changing nozzle orientation. Also Muller examined the effect of initial flow direction on the base pressure of nozzle[13]. The effect of base cavities on the base pressure at various angles was studied by Tanner[14]. He found an increase in base pressure by applying cavities, and hence reduction in base drags. The experimental investigation to study the effects of micro jets under the influence of over, under and correct expansion to control the base drag was studied by Rathakrishnan and others[15-22]. The result was very effective in terms of percentage, as micro jets reduced the base drag without affecting the wall pressure distribution. It is found that many techniques can be used to reduce or even suppress the flow separation. The experimental investigation to study the effects of micro jets under the influence of over, under and correct expansion to control the base drag was studied by Khan and others [20-27]. The result was very effective in terms of percentage, as micro jets reduced the base drag without affecting the wall pressure distribution. It is found that many techniques can be used to reduce or even suppress the flow separation.

Therefore in this study, we have employed micro jets as active control devices in our examination, the correlation of base pressure change with flow Mach number has been demonstrated at different L/D ratios.

\section{Experimental Procedure}

The fringed nozzle-enlarged duct is fixed at the end of the settling chamber by a slot holder arrangement. The base pressure taps and wall pressure taps are measured matching the channels of pressure sensors connected on bread board to a data logger at a time in each run for different Mach numbers and expansion levels. Pressure sensors used for this experiment are Honeywell TruStability ${ }^{\circledR}$ Board Mount Pressure Sensors, HSC Series - High Accuracy, Low Pressure Sensors - HSCDANN015PAAA5 (Absolute) and HSCDANN010BGAA5 (Gauge). Data acquisition is done with the help of Graphtec MIDI LOGGER GL820, with a 20- channel input. The model area ratio $(\mathrm{D} 2 / \mathrm{d} 2)$ is varied in the range from 1.5 to 4 . The $\mathrm{L} / \mathrm{D}$ ratio is another variable parameter 4, 5, 6 for pipe diameters $19 \mathrm{~mm}, 16 \mathrm{~mm}$, and $13 \mathrm{~mm}$ respectively. NPR can be calculated accurately, while Mach number can be estimated from isentropic relationships. The measurements include the stagnation pressure of the settling chamber, the base pressure, and the wall pressure distribution along the length of the duct. All of the pressures are measured using absolute pressure sensors, except for the settling chamber pressure, which is measured using gauge pressure sensor. A data logger is used for data acquisition. Tests done using pressure sensors and data logger for a particular case with repeated testing for the same, showed that it was repeatable within $\pm 2 \sim 3 \%$ accuracy with the previous results of the same case.

\section{Results and Discussion}

One of the common problems faced while working in the area of suddenly expanded flow field is that the pressure field in the enlarged duct becomes oscillatory because of the "Ejector Pump" action at the base region i.e. the vortices are getting formed at the base because of expansion of the shear layer from the nozzle and getting ejected to the main flow continuously. In the literature this action was referred to as the "Jet Pump action". This action renders the flow in the duct to become oscillatory. These oscillations are reflected as variation in the wall pressure distribution of the enlarged duct. Therefore, it becomes mandatory on the part of a researcher working on sudden expansion problems to monitor wall pressure distributions in the enlarged duct. In other words when we employ a control to modify the base pressure level, there is a possibility that the control might augment the oscillatory nature of the flow field in the enlarged duct. To account for this undesirable effect (aggravating the oscillatory nature of the flow field) wall pressure distribution in the enlarged duct was measured for all combination of parameters of the present investigation.

\section{Results for Correctly Expanded Jets:}

Wall pressure results for $\mathrm{L} / \mathrm{D}=1$ to 4 for correctly expanded jets are shown in Figs. 1((a) to (d)). From figure 1(a) it is seen that flow is not attached with wall and due to extremely short duct length and due to the influence of the back pressure the wall pressure values are much closed to the ambient pressure. Wall pressure with and without control are identical. Also, it should be kept in mind that the jets are correctly expanded. Fig. 1 (b) presents the wall pressure distribution for $\mathrm{L} / \mathrm{D}=2$. It is observed that the flow is attached with the duct wall and the reattachment point seems to be at $\mathrm{x} / \mathrm{L}=0.3$. For this case also wall pressure field remains identical and there is smooth recovery of the flow in the enlarged duct. Almost similar results are seen for $\mathrm{L} / \mathrm{D}=3$ and 4 in Fig. 1((c) to (d)). Results of wall pressure for L/D = 5 and 6 are shown in Figs. 3((a) to (b)). Here, once again the flow field is identical with and without control and in both the cases the recovery of the wall pressure is very smooth, and fluctuations in wall pressure field are observed. Also, for both the cases the location of reattachment point seems to be at $x / L=0.2$. Results for $\mathrm{L} / \mathrm{D}=8$ and 10 are shown in Figs. 3((c) to (d)). These figures indicate peculiar phenomenon and are totally different from all the results for lower L/Ds. It 
is seen that there is strong oblique shock wave present at $\mathrm{x} / \mathrm{L}=0$ for both the $\mathrm{L} / \mathrm{Ds}$ namely $\mathrm{L} / \mathrm{D}=8$ and 10 and the wall pressure nearly becomes equal to the ambient pressure and then again flow undergoes through the expansion fan resulting in significant reduction in the wall pressure at $\mathrm{x} / \mathrm{L}=0.05$ and again there is increase in the wall pressure due to the presence of oblique shock wave and the location of the shock wave is at $\mathrm{x} / \mathrm{L}=0.1$. Further, at $\mathrm{x} / \mathrm{L}=0.15$ the flow in the enlarged duct has almost achieved the value of the atmospheric pressure, and for $\mathrm{x} / \mathrm{L}=0.2$ and above it remains constant and flows with and without control are identical which means when controls in the form of micro jets are employed they do not disturb the flow field in the duct.

\section{Results for Under Expanded Jets:}

Wall pressure results for $\mathrm{L} / \mathrm{D}=1$ to 4 for under expanded jets are shown in Figs. 2((a) to (d)). From figure 2(a) it is seen that flow remains attached with wall even though L/D is as low as $=1$, and the reattachment point seems to be at $\mathrm{x} / \mathrm{L}=0.5$ and control results in marginal decrease in the wall pressure otherwise the wall pressure flow field with and without control remains same. Further, it is observed that due to the extremely short length the flow in the duct is influenced by the back pressure leading to the larger values of the wall pressure.

Fig. 2 (b) presents the wall pressure distribution for $\mathrm{L} / \mathrm{D}=2$. It is observed that the flow is attached with the duct wall and the reattachment point seems to be at $\mathrm{x} / \mathrm{L}=0.28$. For this case also wall pressure field remains almost identical and there is no smooth recovery of the flow in the enlarged duct due to the presence of the waves as the jets under expanded and the flow will pass through the expansion fan. Immediately at the exit from the nozzle there is an oblique shock at $x / 1=0$ and hence there sudden jump in wall pressure and then it under goes through the expansion fan at $\mathrm{x} / \mathrm{L}=0.28$, resulting in decrease of pressure.

Results for L/D = 3 and 4 are shown in Fig. 2((c) to (d)). For both the L/Ds the results are on the similar lines for $\mathrm{L} / \mathrm{D}=3$ and 4 the reattachment points are at $\mathrm{x} / \mathrm{L}=0.2$ and 0.15 respectively. For $\mathrm{L} / \mathrm{D}=3$ there is a steep rise in wall pressure at $\mathrm{x} / \mathrm{L}=0.6$ whereas, for $\mathrm{L} / \mathrm{D}=4$, it happens at $\mathrm{x} / \mathrm{L}=0.5$ and later on there is smooth recovery of the wall pressure becoming almost equal to the ambient pressure and for both the L/Ds the wall pressure with and without control are the same.

Results of wall pressure for L/D = 5 and 6 are shown in Figs. 4((a) to (b)). Here, once again the flow field is identical with and without control and in both the cases the recovery of the wall pressure is not smooth rather it wavy in nature, and fluctuations in wall pressure field are observed. The main reason for this trend is due the jet being under expanded. Another observation is that the second jump in wall pressure has shifted back and there is third jump as well this could be due to the larger length of the duct.

Also, for both the cases the location of reattachment point seems to be at $\mathrm{x} / \mathrm{L}=0.1$. Results for $\mathrm{L} / \mathrm{D}=$ 8 and 10 are shown in Figs. 4((c) to (d)). These figures indicate peculiar phenomenon and are totally different from all the results for lower L/Ds. It is seen that there is strong oblique shock wave present at $\mathrm{x} / \mathrm{L}=0,0.15$, $0.2,0.3$ and 0.5 for $\mathrm{L} / \mathrm{D}=8$. For $\mathrm{L} / \mathrm{D}=10$ the wall pressure has one strong shock and rest of the shocks are weak as compared to $\mathrm{L} / \mathrm{D}=8$. The entire flow field is full of waves and flow remains identical with and without control which means when controls in the form of micro jets are employed they do not disturb the flow field in the duct.

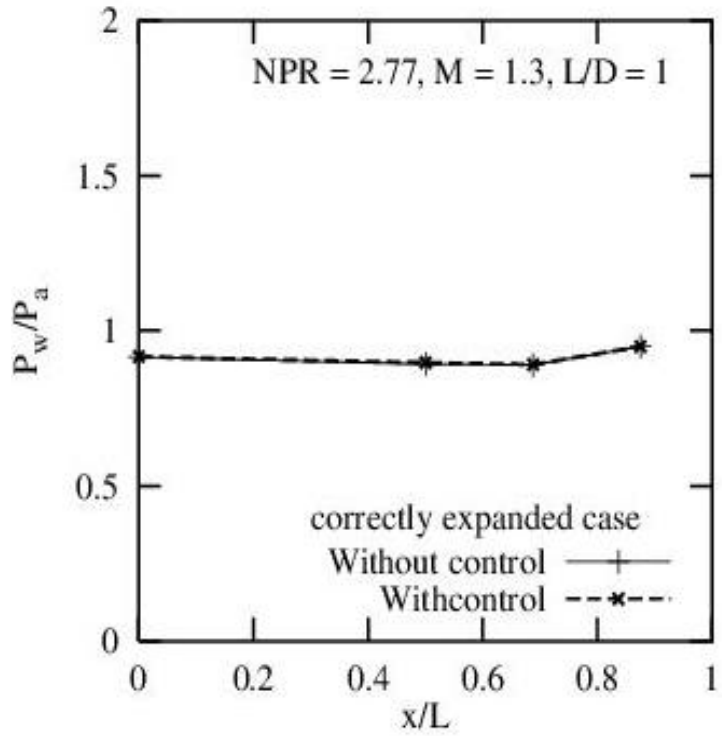

Fig. 1(a)

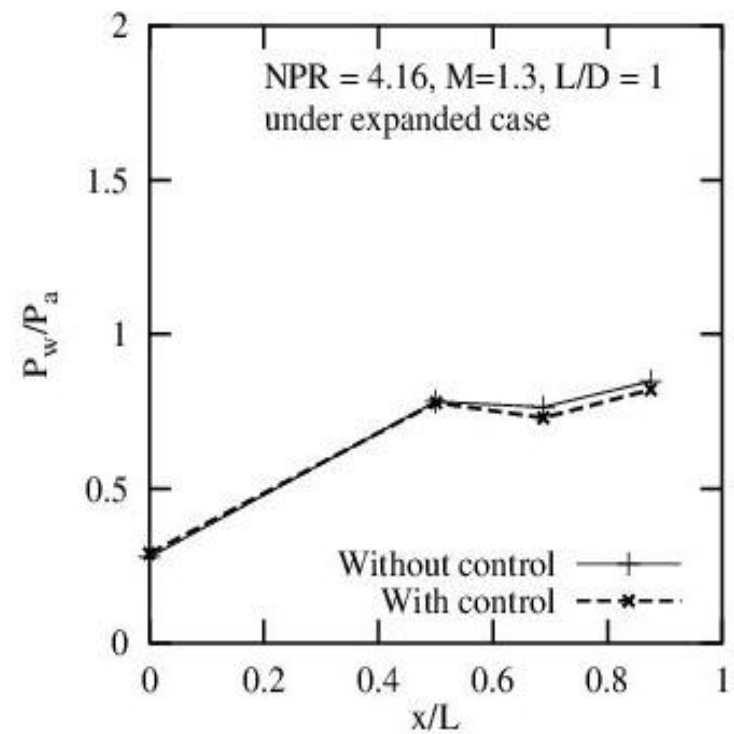

Fig. 2(a) 


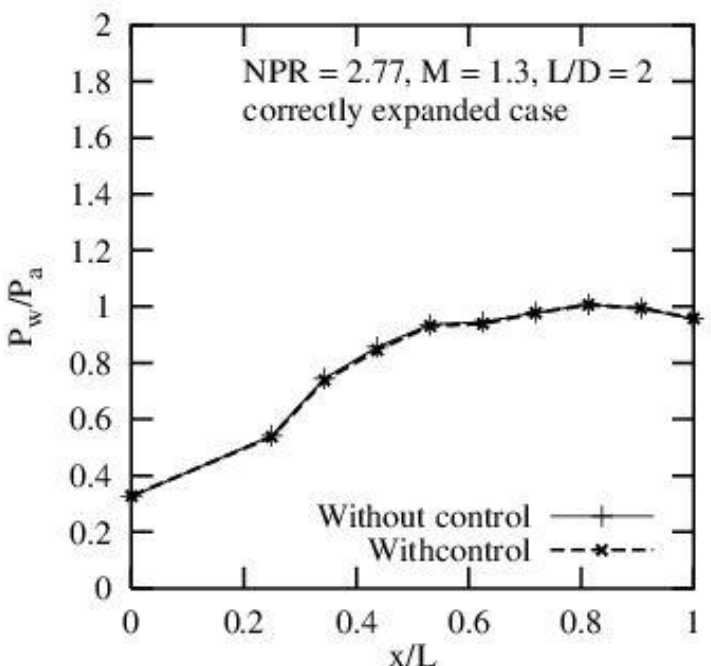

Fig. 1(b)

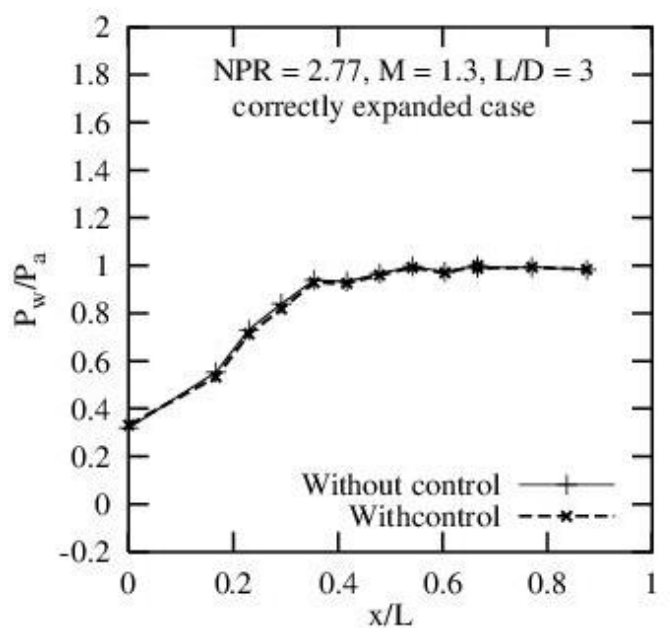

Fig. 1(c)

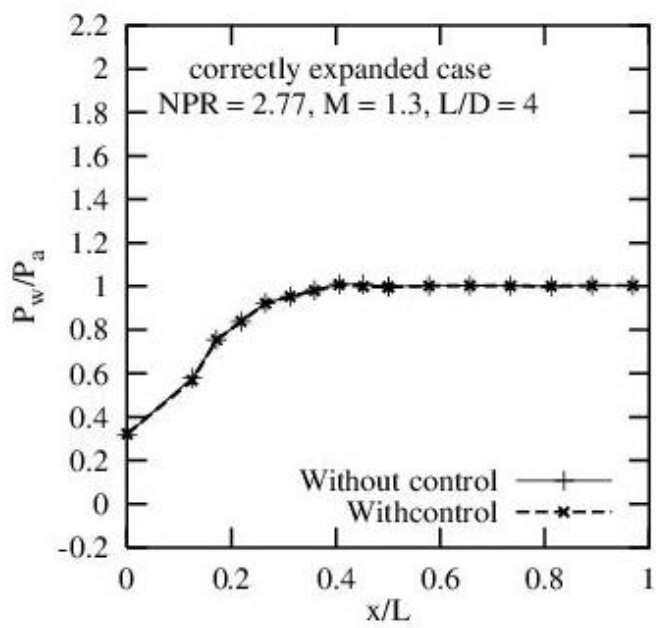

Fig. 1(d)

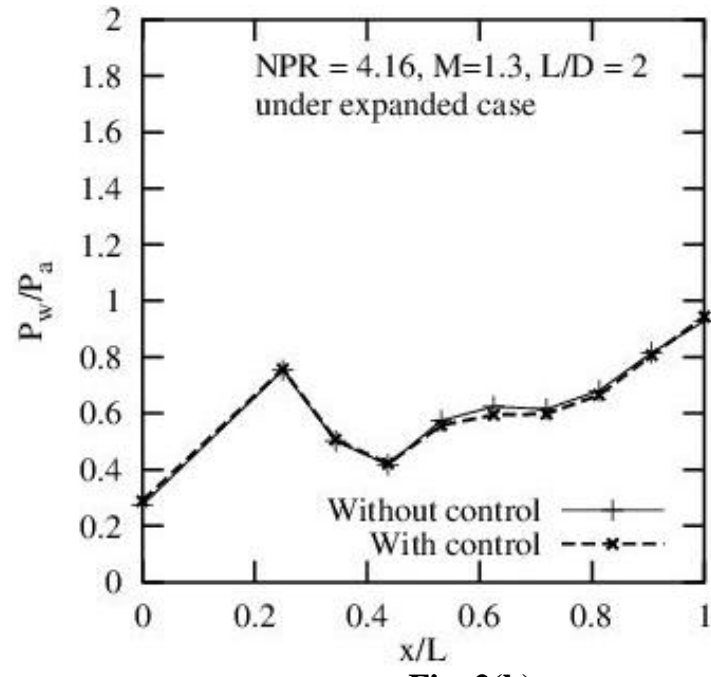

Fig. 2(b)

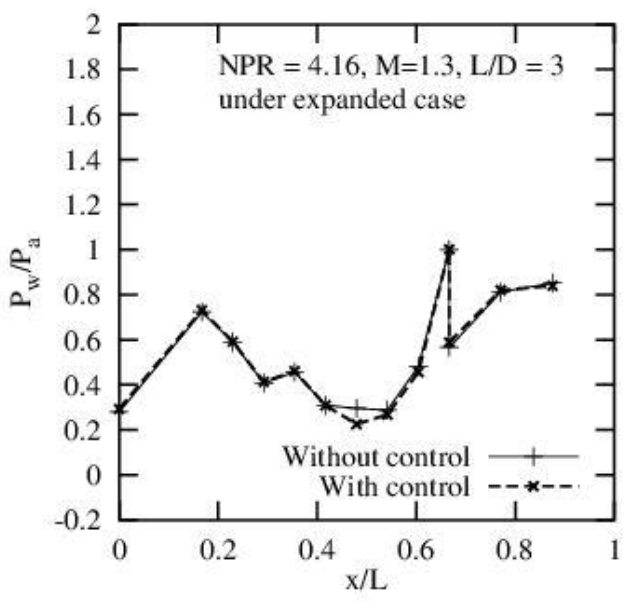

Fig. 2(c)

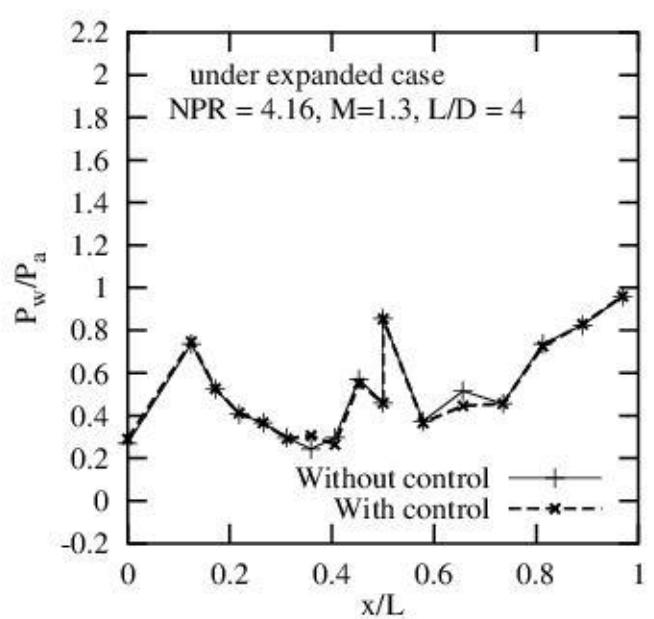

Fig. 2(d) 


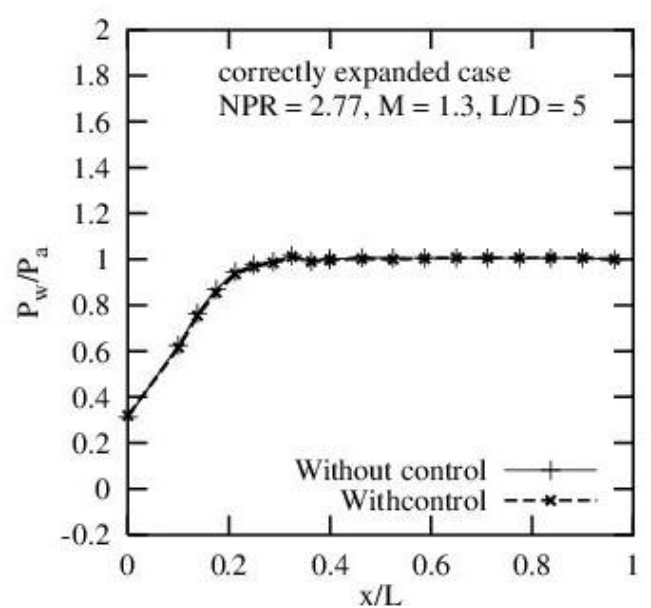

Fig. 3(a)

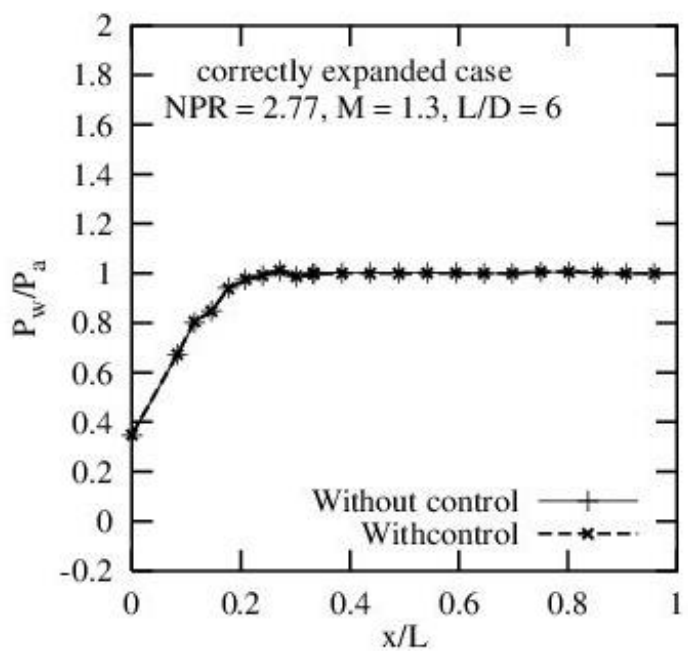

Fig. 3(b)

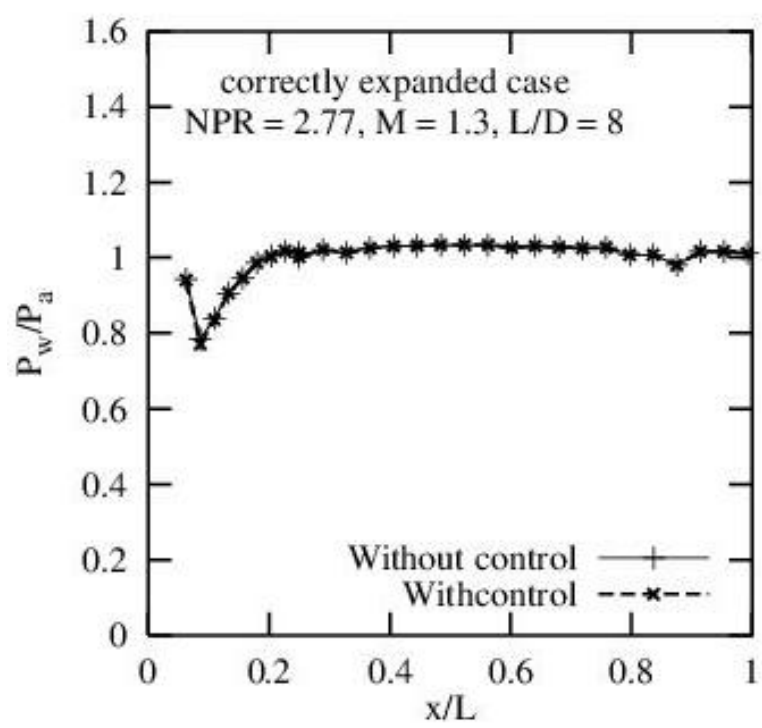

Fig. 3(c)

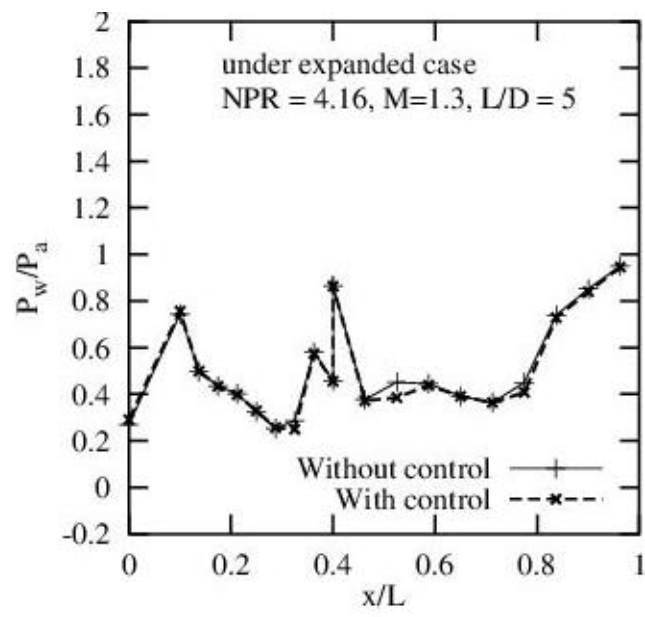

Fig. 4(a)

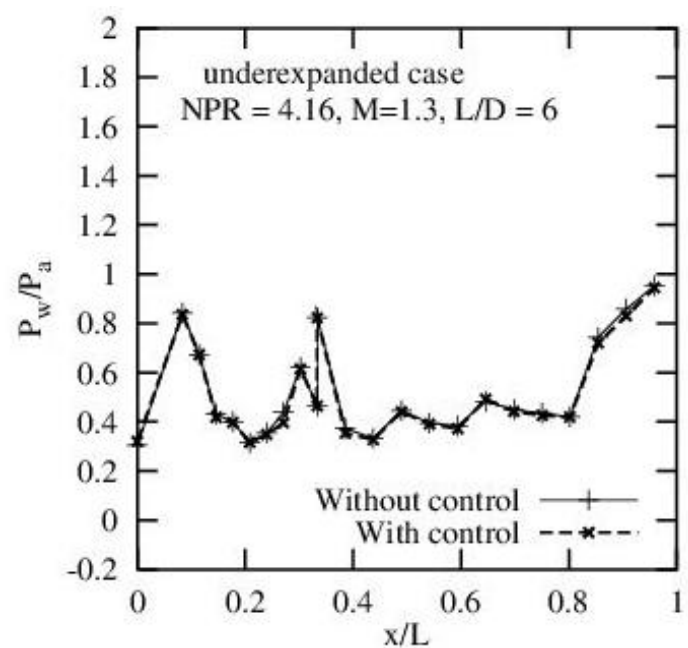

Fig. 4(b)

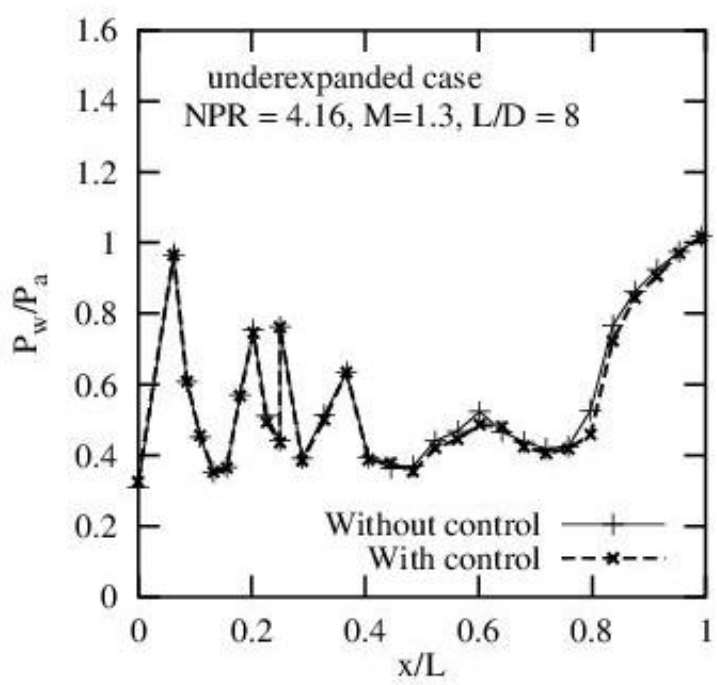

Fig. 4(c) 


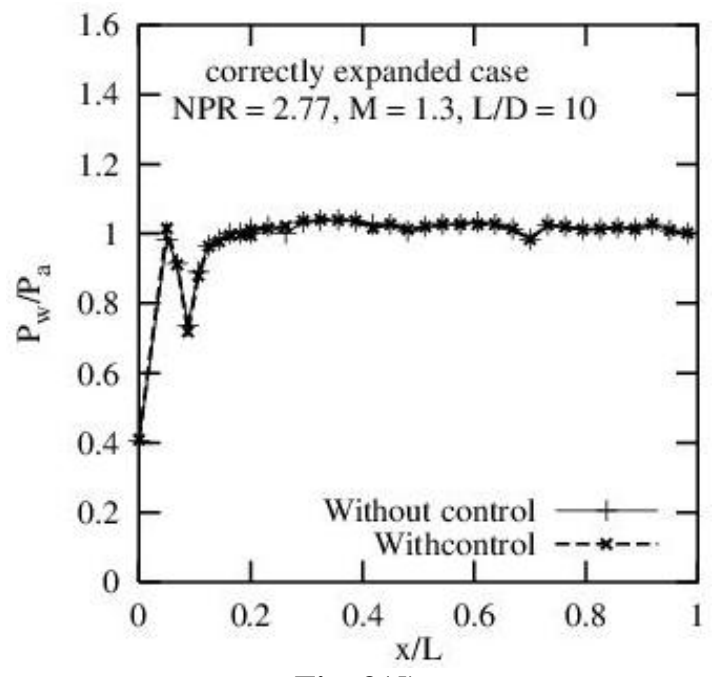

Fig. 3(d)

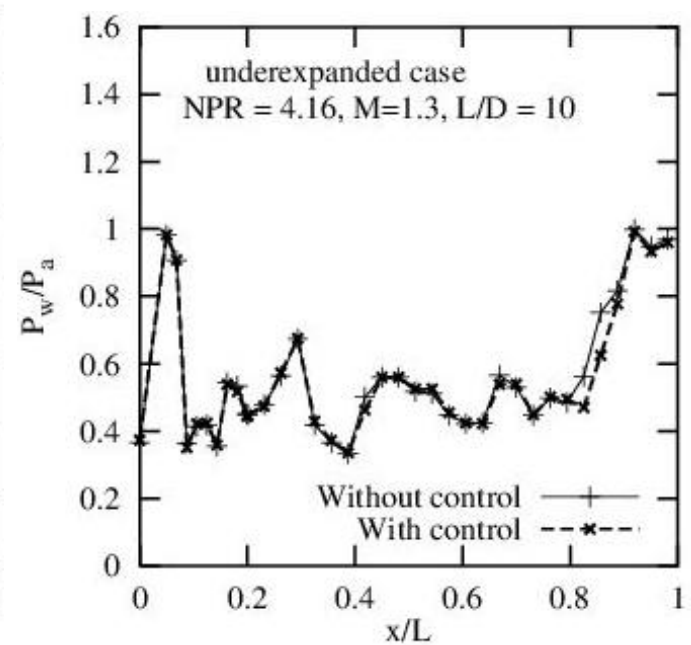

Fig. 4(d)

\section{Conclusion}

From the above discussion we can draw the following conclusions:

- Wall pressure results for correctly expanded and under expended jets indicate that the flow in the enlarged duct remains attached for $\mathrm{L} / \mathrm{Ds}$ including at $\mathrm{L} / \mathrm{D}=1$. Also, it is found that the wall pressure flow field in the duct for with and without control are identical and the control in the form of the micro jets does disturb the flow field.

- Also, for all the L/Ds for correctly expanded jets the location of reattachment point seems to be between $\mathrm{x} / \mathrm{L}=0.2$ to 0.3 , however this value is same for lower $\mathrm{L} / \mathrm{Ds}$ for under expanded jet as well.

- Results for $\mathrm{L} / \mathrm{D}=8$ and 10 for correctly expanded jets indicate peculiar phenomenon and are totally different from all the results for lower L/Ds. It is seen that there is strong oblique shock wave present at $\mathrm{x} / \mathrm{L}=0$ for both the $\mathrm{L} / \mathrm{Ds}$ namely $\mathrm{L} / \mathrm{D}=8$ and 10 and the wall pressure nearly becomes equal to the ambient pressure and then again flow undergoes through the expansion fan resulting in significant reduction in the wall pressure at $\mathrm{x} / \mathrm{L}=0.05$ and again there is increase in the wall pressure due to the presence of oblique shock wave and the location of the shock wave is at $\mathrm{x} / \mathrm{L}=0.1$. Further, at $\mathrm{x} / \mathrm{L}=0.15$ the flow in the enlarged duct has almost achieved the value of the atmospheric pressure, and for $\mathrm{x} / \mathrm{L}=0.2$ and above it remains constant.

- Wall pressure results for under expanded jets indicate that control results in marginal decrease in the wall pressure otherwise the wall pressure flow field with and without control remains same.

- Further, it is observed that due to the extremely short length the flow in the duct is influenced by the back pressure leading to the larger values of the wall pressure.

- $\quad$ Results of wall pressure for under expanded jets have indicated that for $\mathrm{L} / \mathrm{D}=5$ and 6 the wall pressure is not smooth rather it is wavy in nature, and fluctuations in wall pressure field are observed. The main reason for this trend is due the jet being under expanded. Another observation is that the second jump in wall pressure has shifted back and there is third jump as well this could be due to the larger length of the duct.

- Results for $\mathrm{L} / \mathrm{D}=8$ and 10 for under expanded jets indicate peculiar phenomenon and are totally different from all the results for lower L/Ds. It is seen that there is strong oblique shock wave present at $\mathrm{x} / \mathrm{L}=0$, $0.15,0.2,0.3$ and 0.5 for $\mathrm{L} / \mathrm{D}=8$. For $\mathrm{L} / \mathrm{D}=10$ the wall pressure has one strong shock and rest of the shocks are weak as compared to $L / D=8$. The entire flow field is full of waves but still flow remains identical with and without control which means when controls in the form of micro jets are employed they do not disturb the flow field in the duct.

\section{References}

[1]. Lefrancois, E., G. Dhatt, and D. Vandromme, Fluid-structural interaction with application to rocket engines. International journal for numerical methods in fluids, 1999. 30(7): p. 865-895.

[2]. Blades, E.L., E.A. Luke, and J. Ruf, Fully Coupled Fluid-Structure Interaction Simulations of Rocket Engine Side Loads. AIAA paper, 2012. 3969.

[3]. Brown, A.M., et al. Characterization of side load phenomena using measurement of fluid/structure interaction. in 38th Joint Propulsion Conference and Exhibit, AIAA Paper. 2002. 
[4]. Ostlund, J. and B. Muhammad-Klingmann, Supersonic flow separation with application to rocket engine nozzles. Applied Mechanics Reviews, 2005. 58(3): p. 143-177.

[5]. Dumnov, G. Unsteady side-loads acting on the nozzle with developed separation zone. in 32nd Joint Propulsion Conference and Exhibit, AIAA Paper. 1996.

[6]. Srivastava, N., P.T. Tkacik, and R.G. Keanini, Influence of nozzle random side loads on launch vehicle dynamics. Journal of Applied Physics, 2010. 108(4): p. 044911.

[7]. Frey, M. and G. Hagemann. Flow separation and side-loads in rocket nozzles. in 35th AIAA/ASME/SAE/ASEE Joint Propulsion Conference and Exhibit. 1999.

[8]. Damgaard, T., J. Östlund, and M. Frey, Side-load phenomena in highly overexpanded rocket nozzles. Journal of Propulsion and Power, 2004. 20(4): p. 695-704.

[9]. Verma, S.B., R. Stark, and O. Haidn, Relation between shock unsteadiness and the origin of side-loads inside a thrust optimized parabolic rocket nozzle. Aerospace Science and Technology, 2006. 10(6): p. 474-483.

[10]. Lüdeke, H. and J. Calvo, A Fluid Structure Coupling of the Ariane-5 During Start Phase by DES. 2008.

[11]. Wick, R.S., The effect of boundary layer on sonic flow through an abrupt cross-sectional area change. Journal of the Aeronautical Sciences, 2012.

[12]. Menon, N. and B. Skews, 3-D shock structure in underexpanded supersonic jets from elliptical and rectangular exits, in Shock Waves2005, Springer. p. 529-534.

[13]. HALL, J., CR, T. Mueller, and P.J. Roache, Influence of initial flow direction on the turbulent base pressure in supersonic axisymmetric flow. Journal of Spacecraft and Rockets, 1970. 7(12): p. 1484-1488.

[14]. Tanner, M., Base cavity at angles of incidence. AIAA Journal, 1988. 26(3): p. 376-377.

[15]. Khan, S.A. and E. Rathakrishnan, Active control of suddenly expanded flows from overexpanded nozzles. International Journal of Turbo and Jet Engines, 2002. 19(1-2): p. 119-126.

[16]. Khan, S.A. and E. Rathakrishnan, Control of suddenly expanded flows with micro-jets. International Journal of Turbo and Jet Engines, 2003. 20(1): p. 63-82.

[17]. Khan, S. and E. Rathakrishnan, Control of suddenly expanded flow. Aircraft Engineering and Aerospace Technology, 2006. 78(4): p. 293-309

[18]. Khan, S.A. and E. Rathakrishnan, Active Control of Suddenly Expanded Flows from Underexpanded Nozzles. International Journal of Turbo and Jet Engines, 2004. 21(4): p. 233-254.

[19]. Ashfaq, S., S.A. Khan, and E. Rathakrishnan, Active Control of Flow through the Nozzles at Sonic Mach Number. International Journal of Emerging trends in Engineering and Development, 2013. 2(3): p. 73-82.

[20]. Chaudhary, Z.I., et al., Experimental Investigation on the Effectiveness of Active Control Mechanism on Base Pressure at Low Supersonic Mach Numbers, in Innovative Design and Development Practices in Aerospace and Automotive Engineering2017, Springer. p. 197-209.

[21]. M. Ahmed Ali Baig, et al., Control of base flows with micro jets. International Journal of Turbo and Jet Engines, 2011. 28(1): p. 59-69.

[22]. M. Ahmed Ali Baig, S.A. Khan, and E. Rathakrishnan, Active Control Of Base Pressure In Suddenly Expanded Flow For Area Ratio 4.84. International Journal of Engineering Science and Technology, 2012. 4(5): p. 1892-1902.

[23]. Khan, S., M. Bashir, and M.A. Ullah, An investigation of base flow control by wall pressure analysis in a suddenly expansion nozzle. 2016.

[24]. Chaudhary, Z., et al., Experimental investigation of the base flow from the nozzles with sudden expansion. International Journal of Applied Engineering Research. 10(92): p. 2015.

[25]. M. Ahmed Ali Baig, S. A. Khan and E. Rathakrishnan "Effect of Mach number In a Suddenly Expanded Flow for Area Ratio 4.84" International Journal of Engineering Research and Applications (IJERA) Vol.2, N0.7, pp 593-599, July 2012

[26]. M. Ahmed Ali Baig, S.A. Khan, and E. Rathakrishnan, Control of Nozzle Flow in Suddenly Expanded Duct with Micro Jets. International Journal of Engineering Science \& Advanced Technology [IJESAT]. 2: p. 789-795.

[27]. Ashfaq, S., S. Khan, and E. Rathakrishnan, Control of suddenly expanded flow for area ratio 3.61. International Journal of Advanced Scientific and Technical Research, 2013(3): p. 798-807. 